\title{
VARIATIONS IN DEPRESSIVE AFFECTS DUE TO DIFFERENCES IN GENDER AND RESIDENCE
}

\author{
Sultana Zakiya Huq*
}

Teachers' Training College, Rajshahi.

\begin{abstract}
The study explores the phenomenon of depression as a function of gender and residence. A total of 40 respondents constituted the sample. The age of the respondents ranged from 40-65 years. A $2 \times 2$ factorial design representing two levels of gender (Male/Female) and two levels of residential background (Urban/Rural) was used. Two hypotheses were formulated. The first hypothesis states that female would exhibit more depressive symptoms than the males. The second hypothesis states that respondents with rural residential background would exhibit more depressive symptoms than the respondents with urban residential background. The statistical technique of analysis of variance (ANOVA) was used for the analysis of data. The results provided empirical support to the second hypothesis. It was found that respondents with rural residential background expressed significantly more depressive symptoms than the respondents with urban residential background.
\end{abstract}

Key words: Depressive affect, self-esteem, adolescence, brain chemistry, mental health.

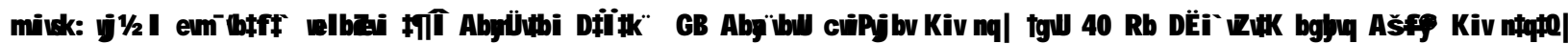

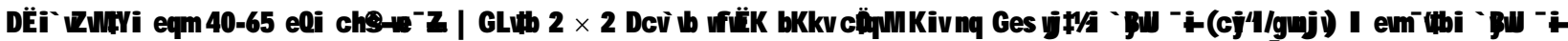

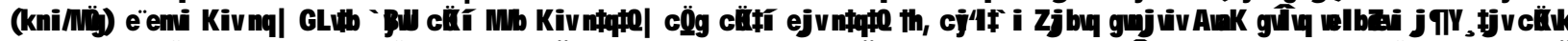

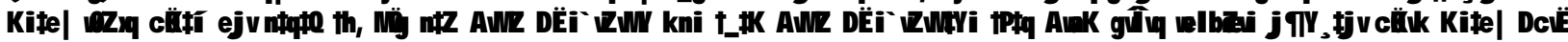

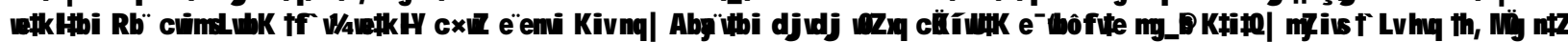

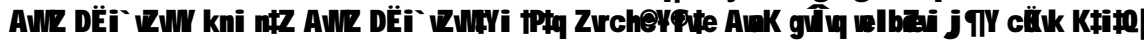

\section{Introduction}

The most important correlates of depression are loneliness, loss of relationship, guilt and regret, failure and disappointment in social context. Human beings are basically social animals. Hence the elements that emerge from social interactions play an important role in maintaining social relationships. The absence of social relationships in human beings lead to the development of depressive symptoms (Bowlby 1969; 1973; Shaver and Freeman 1976).

Several studies, for example, Ostrov and Offer (1980) showed that abandoned young children protest by scramming, and then they feel guilty withdrawal and finally become detached and apathetic. Hence social contact is a powerful need in the everyday interaction for keeping the individuals in a touch with other members of the society. The investigator also showed that 1 in 5 Americans do not have friends with whom they could discuss a personal problem.

It is true that almost all of us are lonely sometimes. Findings reported by Ostrov and Offer (1980) showed that about $20 \%$ of American people feel lonely at one time in their lives. It was also reported that between $10 \%$ and $20 \%$ of all children and adolescents in American society are lonely a lot of the time and they fail to achieve required grades necessary in schools.

*Lecturer, Guidance and Counselling
Loneliness is the basic elements of depression. Loneliness refers to the missing and longing for some kind of human interaction. The missing contract leading to loneliness varies greatly. There may be social loneliness, emotional loneliness and spiritual loneliness. All these forms of loneliness contribute to depression.

Flanders (1976) found that about $26 \%$ of college students and over $80 \%$ of adults reported their depressive condition due to being alone. Rebinstein and Shaver (1982) found four kinds of emotions associated with depression. These emotional expressions create the conditions of self-esteem of the individual. Those emotional feelings seem to lower the self-esteem of the individual. Those low self-esteems contribute to the development of depressive affect.

Gordon (1976) found that lose of relationship and poor family atmosphere create circumstances that force the individuals to move towards depression. Fischer and Phillips (1982) observed that the discrepancy between what the individuals want from society and what they get actually generates disappointment. Again a mobile society forces the members of the community to become apart from each other. These create shyness, lack of social skills and low self-esteem. Thus a condition of isolation emerges. Cultural values of competition and independence may also lead the individuals to become isolated from friends and other relations. In a word, loneliness and isolation are complementary and jointly 
contribute to the development of depressive symptoms. Horowtiz, French and Anderson (1982) found that interpersonal successes and failures are dependent on individual's social conditions of being lonely. Lonely persons attribute their failure to lack of ability and abuse themselves. They are not capable to provide solutions to interpersonal problems. They lack in social skills. All these personal disabilities lead to the progress of depression.

Rock (1984) has provided extensive research documents of low self-esteem, shame and self-blame that strongly motivated individuals to avoid contact with others. Chopich and Paul (1990) observed that low self-esteem create a fragile ego. Such individuals avoid criticism and discount to face the reality. These social, environmental and interpersonal difficulties are responsible for the development of depression.

It is, therefore, evident that depression has its origin in interpersonal, inter-group and environmental atmospheres. The present study would explore depression in these interpersonal, inter-group and environmental conditions in males and females with urban and rural residential background.

\section{Overview}

Studies on depression have shown that depression is a common phenomenon in modern society. Western culture conceives depression seriously and various attempts have been made to understand and explain the causative factors of depression. Some relevant studies of depression have been described below.

Wilcoxon et al. (1976) reported that one third of all people seeing a psychiatrist are depressed. National Institute of Mental Health (1971) observed that depression is the first of second frequent reason why people are admitted to the Psychiatric wards in general hospital. It was also reported that about 1 in 10 males and 1 in 4 females suffer from depression. It was also reported that women are twice depressed than men. Research findings also showed that men get over jobs. Women get upset over relationships. Married people are depressed than single people.

McCoy (1982) reported that in the U.S.A, one person attempts suicide in every minute and more persons in every 24 minutes succeeds in suicide. Almost 500,000 teenagers attempt suicide each year. The investigator concluded that suicide is a permanent and desperate solution to a temporary problem. Thus depression in affluent country like America has created problem in social interpersonal relationship.
Meyers (1992) conducted a study and reported that depression occurs in several common situations. These are death or loss of a loved one, when feeling lowesteem, when pessimistic and when having suicidal thoughts. Again feelings of guilt and shame may also cause depression and have affected the happiness of American people to a great extent. The investigators also recorded that unmarried males lead an unhappy life and they are easily become victim of depression.

Waterman (1993) found personal problems to be highly correlated with depression. Sheldon, Elliot, Kim and Kasser (2001) reported that depression is positively related with the needs of happiness. In the absence of caring relationship, depression may gradually occur. Diener, Sandvik and Pavot (1990) supported these findings and concluded that impossible wishes are the factors for the emergence of depression. Myers (1992) found that lose of jobs, separation from loving spouse and deprivation from a favorite hobby may lead to depression.

Harrington (1990) conducted a study to explore history and gender factors in depression. He followed up 80 children and adolescents hospitalized for serious depression and found $60 \%$ to become depressed again before they were 30 . The investigator reported that several childhood experiences have been related to adult depression. These are (1) feeling of guilty as a child, (2) A strained relationship with the same-sexed parent, (3) Depressed mother who needs help for caring her children and (4) Dominant and over protected parent using poor child rearing practices.

Kandel and Davis (1982) conducted a large study of depressed adolescents and found low self-esteem, antisocial behaviour, over-involvement with peer group, over-involvement with parents, authoritarian parents and depressed parents as causative factors of depression.

Coryell et al. (1992) followed adults who had never been diagnosed as mentally ill. It was found that $12 \%$ developed major depression within 6 years. Younger persons under 40 years were three times more depressed than the older people. A case of divorce increases the chances of getting depressed for women. Women are diagnosed as depressed twice of men. Higher education increases the risk of depression for women but decreases the risk of depression for men. Women living on farms are prone to depression.

Nolen-Hoeksens and Girgus (1994) conducted empirical study to explain gender discrimination in depression. It was found that depression is likely to occur in 
unmarried women who are poor and have little education. The investigation identified several situations who are poor and have little education. The investigators identified several situations that lead women to become depressed in higher number than men. First of all women are taught to confirm, to serve and to please others in a society. Within this context about $50 \%$ of women are physically and sexually abused before age 21. Another $25 \%$ are abused or coerced in later relationship and $70 \%$ are sexually harassed. It was found that $75 \%$ of all people in poverty are women with children. Thus women are victimized in all ages leading to the development of depression in higher proportion than men.

McGrath et al. (1990) reported an amazing finding about depression of boys and girls at puberty. Boys are more likely to be depressed than girls before developing sexually. But afterwards girls become twice than the boys while boys are turned to delinquency. However, all girls at puberty are not depressed. Adolescent girls who get depressed tend to become over-concerned and overinvolved emotionally with their mother's problems in a stressful home. Boys do not show this sensitivity and involvement in family problems.

Levitt and Lubin (1975) reported some behaviours create depression. These are complaints about money, job, poor memory, confusion, loneliness, lack of care and love, running away from home, obsessed with guilt, being a victim of suicidal threats or attempts. Beck (1973) reported some behavioral deficits of depression. These are socially withdrawn, difficulty in communication, slower speech, loss of apathetic, weight changes, less sexual activity, poor personal grooming and doing less fortune. Lewinsohn (1975) identified several emotion reactions of depression. These are sadness, emptiness, nervous or restless, irritability and over-reactions to criticism. Depressed people also feel apathetic and socially abandoned. They show less interest in relationship, sex, food, drink, music and current events. Levitt and lubin found 54 symptoms of depression. Some of these symptoms are poor social skills, low self-concept, lack of self-confidence and motivation, pessimism, difficulty in sleeping, excessive sleeping, higher activity, indigestion, constipation, headache, dizziness and somatic problems or complaints.

An overview of relevant studies stated above shows that depression may be regarded as symptoms of a large number of interrelated psychological, social and economic factors. Some genetic factors are also found to be associated with depression. It is, therefore, arguable that people in context of Bangladesh would also express depression in a variety of ways. The findings of empirical studies have shown that depression may be regarded as common cold of mental disorders. This common cold in the form of depression slows down many activities and make us gloomy. The present study would focus on these serious forms of depression such as sadness, disappointment, loneliness, self-criticism, low self-concepts, guilt, shame, boredom, tiredness, lack of interests, lack of meaning in life, etc. Investigators reported that depression may be caused by personal history or experiences as well as brain chemistry. Both psychological and physical factors are significant to explain the causal factors of depression. The present study would consider all these factors of depression in males and females with urban and rural residential background in the context of Bangladesh.

\section{Hypothesis}

The study formulated two hypotheses. The first hypothesis was that females would exhibit more depressive symptoms than the males. The second hypothesis was that respondents with rural residential background would exhibit more depressive symptoms than the respondents with urban residential background.

\section{Methods}

Design: The study used a $2 \times 2$ factorial design representing two levels of gender (male/female) and two levels of residential background (urban/rural).

Sample: A total of 40 respondents participated in this study as sample. It was an incidental sample. The age of the respondents ranged from 40-65 and mean age was 45.35. The respondents were equally divided into males and females on the basis of their gender. Each category of males and females were equally divided into urban and rural on the basis of their residential background.

Questionnaire: The study used Bengali adaptation of Depressive Experiences Questionnaire. This Questionnaire was originally developed by Blatt et al (1976). Bengali adaptation of this Questionnaire was done by Huq (2000). The reliability of the Questionnaire was computed using split-half method and the coefficient of correlation was 0.31 . This was computed using Spearman-Brown prophecy formula and the $r$ was 0.47 . The depressive Experiences Questionnaire was 7-point scale. It contains 23 statements. The depressive score was worked out using a formula of highest score minus lowest score divided by two plus lowest score. Using this formula, the depressive score was calculated 92. The individual falling on 92 or above was identified to express depressive symptoms. 


\section{Procedure}

The Depressive Experiences Questionnaire was individually administered on 40 respondents. Each respondent was asked to read the instruction carefully and to give answers by putting a tick $(\sqrt{ })$ mark on the number given below each statement. As soon as the answering of the Questionnaire was completed, the investigator collected the answer sheets for coding. The coding was properly done and the data were subjected to statistical treatment.

\section{Results and Discussion}

The results of the study were computed using statistical technique of analysis of variance (ANOVA). The summary of ANOVA is shown in Table 1. Results showed that a two-way analysis of variance involving gender and residential background was statistically significant $(\mathrm{F}=4.80, \mathrm{df}=1 / 39, \mathrm{P}<0.05)$.

Table 1. ANOVA of gender and residential background on the scores of Depressive Experiences Questionnaire (DEQ).

\begin{tabular}{|l|l|c|l|l|}
\hline $\begin{array}{l}\text { Source of } \\
\text { variation }\end{array}$ & $\begin{array}{l}\text { Sum of } \\
\text { Squares (SS) }\end{array}$ & Df & Mean SS & F-values \\
\hline Gender (A) & 25.60 & 1 & 25.60 & $0.14^{\text {Ns }}$ \\
\hline $\begin{array}{l}\text { Residential } \\
\text { background (B) }\end{array}$ & 504.10 & 1 & 504.10 & $2.80^{\text {Ns }}$ \\
\hline AB & 864.90 & 1 & 8640.90 & $4.80^{*}$ \\
\hline Within cell & 6489 & 36 & 180.25 & \\
\hline Total & 7883.6 & 39 & & \\
\hline
\end{tabular}

$\mathrm{Ns}=$ not significant; $*=\mathrm{P}<0.05$

Table 2. Mean scores and significant mean differences between gender and residential background on the scores of Depressive Experiences Questionnaire (DEQ).

\begin{tabular}{|c|c|c|}
\hline Gender & \multicolumn{2}{|c|}{ Residential background } \\
\hline & Urban & Rural \\
\hline Male & $104.90^{\mathrm{a}}$ & $121.30^{\mathrm{b}}$ \\
\hline Female & $115.80^{\mathrm{c}}$ & $113.60^{\mathrm{c}}$ \\
\hline
\end{tabular}

Common superscripts do not differ significantly. The mean difference was computed by Newman-Keuls formula.

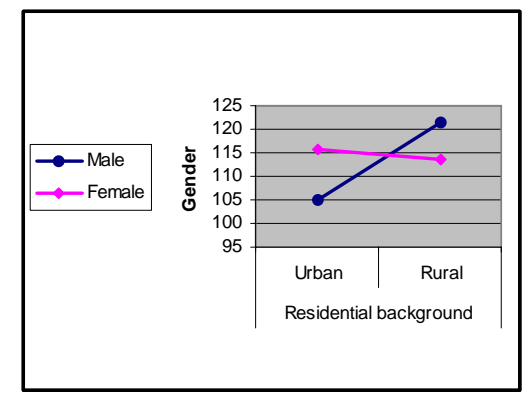

Fig. 1. Two-way interaction between gender and residence.
An inspection of mean scores (Table 2) shows that male respondents with rural residential background $(\mathrm{M}=121.30)$ exhibited significantly more depressive symptoms as compared to male respondents with urban residential background $(M=104.90)$. In case of urban residential background, it was found that female respondents $(M=115.80)$ exhibited significantly more depressive symptoms as compared to male respondents $(\mathrm{M}=104.90)$. In case of rural residential background, it was found that male respondents $(M=121.30)$ exhibited significantly more depressive symptoms as compared to female respondents $(\mathrm{M}=113.60)$. This has effected interaction. The interaction effect has been graphically shown in Fig. 1. Between-group comparison showed that the female respondents with rural residential background ( $M=113.60)$ exhibited significantly more depressive symptoms as compared to male respondents with urban residential background $(M=104.90)$. Again male respondents with rural residential background $(M=121.30)$ exhibited significantly more depressive symptoms as compared to female respondent with urban residential background $(\mathrm{M}=115.80)$

Depression is a complex condition or process in individuals. A seriously depressed person may have no appetite, no pleasure, no energy and no hope. It may involve crying, social withdrawal, being irritable, having no ambition and being pessimistic. A depressed person is a terrible and hopeless person. Under these circumstances, present study has carried out an empirical investigation to locate the present situation about depression in Bangladesh context.

An overview of the main findings of the present study indicates that depression is a current problem in males and females with urban and rural residential background. It is amazing to note that all the respondents obtained depressive scores indicating an overall serious condition in the field of mental health.

The study formulated two hypotheses. The first was that the females would exhibit more depressive symptoms than the males. The results of the study did not support this hypothesis by empirical findings. In spite of it, both males and females obtained such scores that indicate their depressive conditions in social relationships.

The second hypothesis was that respondents with rural residential background would exhibit depressive symptoms in higher degree than the respondents with urban residential background. The data of the study have provided empirical support to this hypothesis. Respondents from rural residential background exhibited significantly more depressive symptoms as 
compared to respondents with urban residential background. However both the groups of urban and rural residential background obtained depressive scores indicating overall depressive condition in respect of their mental health in the perspective of social situations in Bangladesh.

It is reasonable to argue that people become depressed when they fail to fulfill their expectations regarding financial benefits in terms of service, business and agriculture. It is also true that people become depressed due to their failure in family relationships. In the context of Bangladesh, it is found that there is a comprehensive turmoil in economic and social aspects in Bangladesh. But it is comparatively more acute in rural areas than the urban areas. It is, perhaps, these social, economic and psychological conditions that are responsible to make a line of demarcation in depressive affects between urban and rural population.

Some distinctive features emerging from this study were that females in urban areas were found more depressive than the females in rural areas. Thus residential background emerged as a crucial factor to account for depression in males and females.

Previous studies (Coryell et al. 1992) have shown that education is a positive factor for depression in women. The more the women are educated, the more they become depressed. Again divorce, number of children, family conflict and child birth have been identified as some important causes of depression in women. In consideration of these phenomena, it is possible to argue that in urban population, women become more depressed than the men. This finding has provided partial support to first hypothesis of the study that females would exhibit more depressive symptoms than the males.

It was also found that males in rural population were more depressed than the females. One possible reason for this finding might be that men have to bear greater responsibility in maintaining their families. Women, on the other hand, are less educated. Hence, they have limited expectations about their future ambition and they prefer to lead easy-going lives in their day-to-day activities.

In conclusion, it may be said that depression is the necessary evil in society. It is one of the most serious mental problems connected with emotions and psychological activities. It is not a fault with the individual. It is fault with social system. Findings of the present study have successfully revealed that people in Bangladesh are exposed to different social, economic and family problems. These, in turn, create mental health problems in men and women population with urban and rural residential background.

\section{References}

Bowlby J. 1996. Attachment and loss, New York: Basic Books.

Bowlby J. 1973. Separation. New York: Basic Books.M Coping with teenage depression. New York; New American Library.

McGrath D, Keita GP, Strickland BR, Russo NF. 1990. Women and depression; Risk factors and treatment issues Washing, D. C.; American Psychological Association.

Myers DG. 1992. The pursuit of happiness; who is happy and why? New York; William Morrow.

National Institute of Mental Health 1971. Psychiatric service in general hospitals; 1969-1970, mental health statisticsseries A, No. 11 Rockville, MD: NIMH.

Nolen-Hoekma S, Girgus JS. 1994. The emergence of gender differences in depression during adolescence. Psychological Bulletin 115, 424-443.

Ostrov E, Offer D. 1980. Loliness and the adolescent. In J. Hartog, J. R. Audy, \& Y. A. Cohen (Eds.) The Anatomy of Loneliness, (pp.170-185) New York; International University Press.

Rock KS. 1984. Promoting social bonding; Strategies for helping the lonely and socially isolated. American Psychologist, 39, 1389-1407.

Rubinstein C, Shaver P. 1982. The experience of loneliness. In L. A. Peplau \& D. Perlman (Eds), Loneliness; a source book of current theory, research and therapy, (pp. 206233). New York; John Willey \& Sons.

Shaver P, Freeman J. 1976 . Your pursuit of happiness. Psychology today, 10, 3, 26-32.

Sheldon KM, Elliot AJ, Kim Y, Kasser T. 2001. What is satisfying about events? Testing 10 candidates' psychological needs. Journal of Personality and Social Psychology, 80, No. 2

Waterman, A. S. (1993). Two conceptions of happiness; Contrasts of personal expressiveness (eudaimonnia) and hedonic enjoyment. Journal of Personality and social Psychology, 64, 678-691.

Wilcoxon, L. A., Schader, S. L. \& Nelson, R. E. (1976). Behavioral formulations of depression in W. E. Craighead, A. E. Kazdin, \& M. J. Mahoney (Eds.). Behavior Modification, Boston; Houhton-mifflin. 